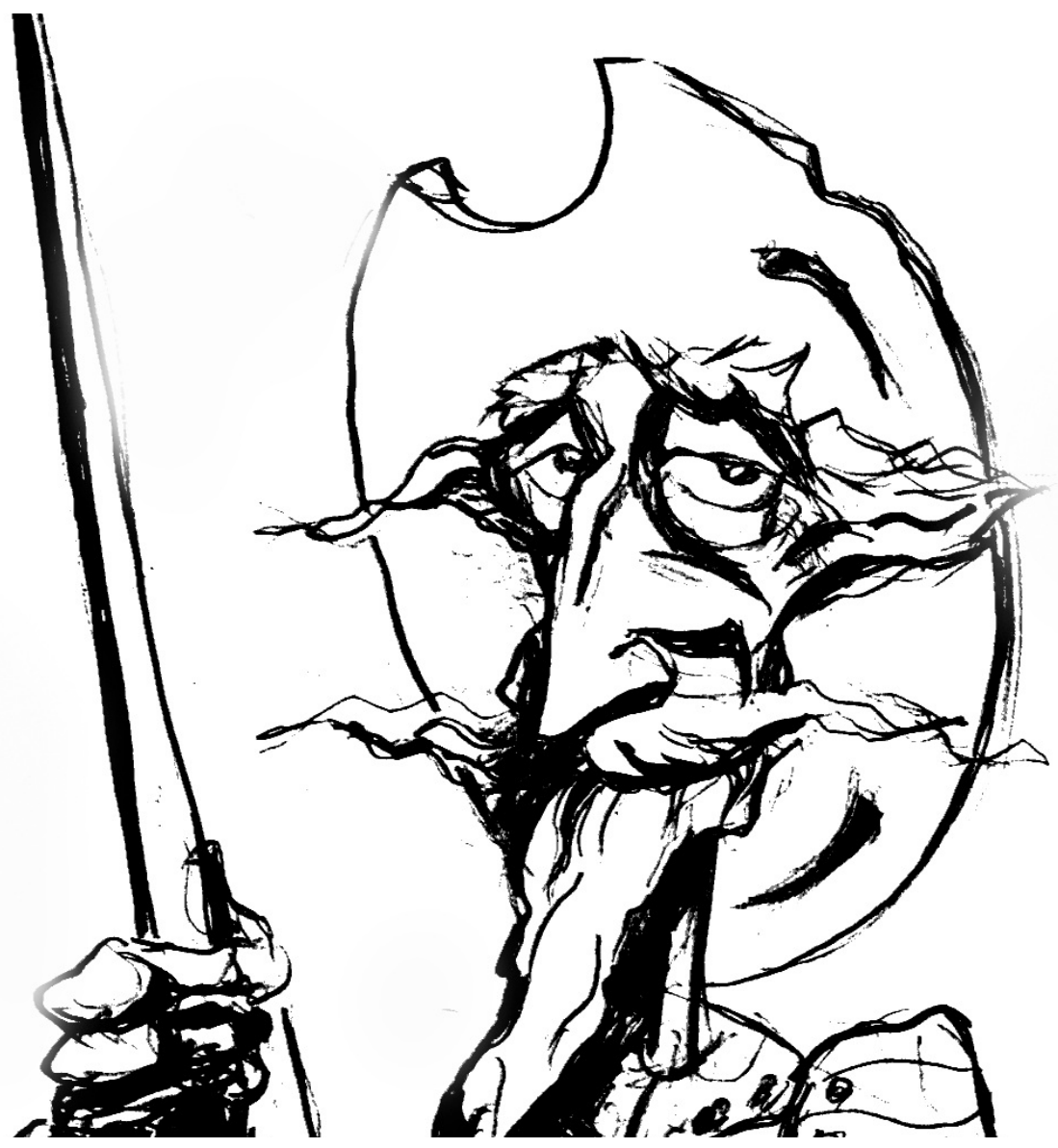

Corregidor evanescente, residencia frustrada, fiadores ejecutados. Redes de poder y tensiones intraelite en el lago Titicaca a inicios del siglo XVII

[Ariel J. Morrone] 



\title{
Corregidor evanescente, residencia frustrada, fiadores ejecutados. Redes de poder $y$ tensiones intraelite en el lago Titicaca a inicios del siglo XVII
}

\author{
Vanishing Corregidor, Spoiled Residencia, Executed Bailors. Power Networks \\ and Intraelite Tensions in Early 17th-Century Titicaca Lake
}

ARIEL J. MORRONE

\section{Resumen}

Este artículo persigue las huellas del capitán Martín Navarro de Hinojosa, corregidor de Paucarcolla (jurisdicción emplazada al norte del lago Titicaca, en el actual departamento de Puno, Perú) en la década de 1610, quien huyera durante la residencia incoada por su sucesor sin haber ajustado sus cuentas con los oficiales de la Real Hacienda de La Paz. Este "escandaloso" acontecimiento reveló un conjunto de tensiones tramadas en el núcleo de la elite paceña; sus episodios permiten vislumbrar el trazado de redes de poder a escala local, regional y extra-regional en el sur andino durante las primeras décadas del siglo XVII.

\begin{abstract}
This article follows the traces of Captain Martín Navarro de Hinojosa, corregidor of Paucarcolla (jurisdiction located north of Lake Titicaca, in the current department of Puno, Peru) in the 1610s, who fled during the residencia initiated by his successor without having adjusted his accounts with the officials of the Real Hacienda of La Paz. This "scandalous" event revealed a set of tensions plotted in the core of the $\mathrm{La}$ Paz elite; its episodes allow us to glimpse the tracing of power networks at local, regional and extra-regional scales in the Southern Andes during the early decades of the seventeenth century.
\end{abstract}

Key Words

Local power; corregidor de indios; residencia; social networks; territory

Poder local; corregidor de indios; residencia; redes sociales; territorio

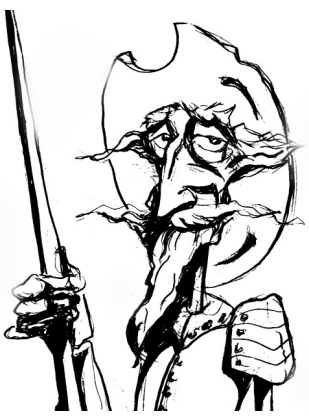

Recibido con pedido de publicación el 27 de mayo de 2019

Aceptado para su publicación el 12 de agosto de 2019

Versión definitiva recibida el 10 de septiembre de 2019

Ariel J. Morrone, Consejo Nacional de Investigaciones Científicas y Técnicas, Universidad de Buenos Aires, Buenos Aires, Argentina; e-mail: arielmorri@yahoo.com.ar 
¿Qué sucedía cuando los mecanismos habituales de la administración virreinal resultaban perturbados por acontecimientos que no respondían al "estilo acostumbrado"? ¿Cómo encastraban los engranajes del gobierno colonial a escala local cuando una de sus piezas giraba en falso? ¿Hasta qué punto estos desacoples tensionaron los equilibrios de poder localmente concertados?

Este trabajo ${ }^{1}$ constituye un avance de investigación sobre los procesos de construcción de redes de poder en la región del lago Titicaca entre finales del siglo XVI y mediados del siglo XVII. Entendemos la cuenca del lago Titicaca como un territorio cruzado por tramas de poder político, un verdadero "tablero de juego" transitado por caciques principales y otras autoridades nativas (a distintos niveles de segmentación y jerarquización), corregidores de indios y curas doctrineros. En tanto "agentes gubernativos intermedios" del poder colonial (Assadourian, 1982 [1979]: 306) y sus verdaderos articuladores a escala local, estas figuras de autoridad estuvieron a cargo del gobierno civil y espiritual de la población nativa, reducida a pueblos de indios luego de la visita general ordenada por el virrey don Francisco de Toledo durante la década de 1570 (Saignes, 1987: 144-145, 1991: 119-120). Pendulando entre la acción mancomunada y el abierto antagonismo, las múltiples formas que adoptaron esas vinculaciones dan cuenta de procesos de construcción, reproducción, consolidación y/o colapso de los liderazgos, toda vez que cada actor debió instituirse como interlocutor válido en sus ámbitos de pertenencia en el fragor de la propia interacción. En efecto, esas trayectorias (paralelas, convergentes o divergentes) pueden pensarse como caminos que cimentaron un espacio político a escala regional, integrado en torno al polo minero de Potosí (y otros asientos menores), los núcleos urbanos del sur andino y sus respectivos entornos rurales. Las redes de relaciones diseñadas a lo largo de los años de ejercicio de sus oficios explican históricamente la configuración del dominio colonial en la región lacustre; entendemos, pues, que el poder se territorializó a través de esas redes (Morrone, 2011, 2012, 2013a, 2015a, 2015b, 2016, 2017, 2018a, 2018b).

Considerar la cuenca del lago Titicaca y sus corregimientos adyacentes como una región histórica busca romper las barreras establecidas por los Estados nacionales decimonónicos sobre espacios que, en tiempos coloniales (e incluso prehispánicos), presentaban altos grados de integración y cuyas poblaciones atravesaron dinámicas sociohistóricas afines. Recuperando la

\footnotetext{
${ }^{1}$ Una versión anterior de este trabajo fue presentada en las X Jornadas de Historia Moderna y Contemporánea, realizadas en Salta (Argentina) del 29 al 31 de agosto de 2018. Agradecemos las observaciones que Juan Pablo Ferreiro y Romina Zamora nos hicieran en aquella oportunidad, como así también las sugerencias de Martín Wasserman, el mapa histórico diseñado por Federico García Blaya y, de igual modo, los comentarios de los réferis anónimos de Revista Prohistoria. Este trabajo fue realizado en el marco de los Proyectos PICT 2016-0481 y UBACyT F291, dirigidos por Ana María Presta.
} 
potencia analítica de un enfoque regional (Barnadas, 1973, 1987; Assadourian, 1982; Stern, 1986 [1982]), evidenciamos que el análisis del rol de las figuras intermedias de gobierno resulta fundamental para conceptualizar el espacio circunlacustre en términos de región, entendida como un proceso histórico de territorialización de relaciones de poder, consolidadas desde la fundación de la ciudad de Nuestra Señora de La Paz (1548) en pleno altiplano aymara, en torno a la encomienda, los emprendimientos agroganaderos hispanocriollos y la participación en los diversificados mercados surandinos. El análisis de prácticas políticas de corte transversal (o trans-lacustre) permite identificar y trazar los vínculos entre actores políticos específicos, protagonistas de episodios "analizadores" de las tramas del poder local en los diferentes confines de lago para dar solidez a nuestra hipótesis acerca de una "región pensada históricamente" (Bandieri, 1996; Benedetti, 2009).

Si las condiciones de reproducción del dominio colonial a escala local estuvieron determinadas, en términos de práctica política, por la interacción de las tres figuras intermedias de autoridad (cacique, corregidor, cura), las mismas reclaman ser estudiadas "en situación" para dar cuenta de los cambios, continuidades, ritmos y modalidades de su impacto sobre los respectivos grupos indígenas. El poder local se configuró, pues, a través de redes de relaciones sociales (familiares, clientelares, de negocios) expresadas territorialmente, y se ejerció de forma "grupalizada" y patrimonializada (Ponce Leiva y Amadori, 2008; Morrone, 2012). En efecto, entendemos que el equipamiento político del territorio (Barriera, 2006) se desplegó sobre un espacio articulado en torno a la producción minera y a los flujos mercantiles (Assadourian, 1982; Glave, 1989).

Instituidos en 1565 por el gobernador Licenciado Lope García de Castro, aunque con efectiva implementación en Charcas durante la década de 1570, los corregidores de indios encarnaron el ejercicio de la jurisdicción real sobre un colectivo de repartimientos indígenas, como oficiales de justicia en primera instancia en los fueros civil y criminal, y como encargados de la exacción tributaria para su posterior entero en las Cajas Reales (Lohmann Villena, 2001 [1957]: 68-77; Tord Nicolini, 1974; Stern, 1986 [1982]: 121-128; Andrien, 1986; Assadourian, 1987; Cook, 2003; Barriera, 2014; Sica, 2014; Robles Bocanegra 2015). Cumplido el plazo establecido para la duración de su oficio, el corregidor debía someterse a un juicio de residencia que evaluaba su desempeño y esclarecía los "alcances", es decir, las diferencias entre los montos establecidos en las tasas y los tributos efectivamente enterados (Lorandi, 2000; Smietniansky, 2007, 2013; Angeli, 2012, 2014; Trujillo, 2016). El ajuste de esas cuentas solía arrojar una diferencia a favor del fisco real, lo cual era subsanado a partir de una obligación de pago que el corregidor asumía cancelar a un corto plazo. Efectuado el pago de los alcances adeudados, el corregidor residenciado quedaba libre de todo cargo. 
Nuestro análisis se despliega a partir del proceso de residencia incoado entre 1616 y 1624 contra el capitán Martín Navarro de Hinojosa, corregidor de Paucarcolla (1612-1614), jurisdicción dependiente de la ciudad de La Paz en la Audiencia de Charcas, emplazada al norte del lago Titicaca. ${ }^{2}$ El hallazgo de esta pieza documental permite echar luz sobre el juego político tramado entre los miembros de la elite paceña de principios del siglo XVII y atender a las formas en que sus vínculos entablados se tensaron al calor de las exigencias de las distintas instancias de la administración virreinal (Barriera, 2006; Smietniansky, 2013: 55-59). En este sentido, no repararemos en la "eficacia" de la residencia como procedimiento contralor, no solo porque nuestro interés principal no radica en el resultado del proceso (es decir, determinar si el corregidor residenciado salió airoso o pagó sus penas), sino porque el caso estudiado presenta una peculiaridad: el corregidor residenciado huyó de su jurisdicción. Al igual que en otros casos de incumplimiento de cargos, este acontecimiento provocó que los fiadores debieran responder con sus bienes ante los jueces oficiales de la Real Hacienda de La Paz. Proponemos, pues, reconstruir la secuencia procesal de este "acontecimiento analizador" que "hizo hablar" a la sociedad en la que estalló, procurando revelar las tensiones subyacentes en la estructura de poder (Lourau, 1970).

Del mismo modo que para acceder a otros oficios regios, los flamantes corregidores de indios precisaban contar con el aval de fiadores que dieran cuenta de la solvencia financiera del nuevo funcionario. Los registros de escrituras públicas de la ciudad de La Paz corroboran que la participación de renombrados vecinos como fiadores de los (muchas veces) recién llegados corregidores constituía una práctica recurrente. La fianza brindaba, en principio, beneficios a ambas partes: el corregidor cumplimentaba los requisitos exigidos para el ejercicio de su oficio, al tiempo que accedía a (o consolidaba su participación en) las redes de poder a escala local y/o regional, mientras que los fiadores incrementaban sus capitales en términos económicos (acceso a nuevas y mayores oportunidades de negocios), políticos (proximidad relacional con el responsable directo del gobierno sobre la población tributaria) y simbólicos (acrecentar la credibilidad, el prestigio y la notoriedad). Los eventuales riesgos de otorgar una fianza se compensaban, según entendemos, con las cuotas de confianza propinadas entre fiadores y corregidores y con los beneficios monetarios que surgieran de sus respectivas actividades económicas, tanto productivas como mercantiles.

A partir de estas consideraciones iniciales, proponemos un relato en siete episodios, acompañados por una serie de cuadros y mapas que ilustran tanto los esquemas de la administración colonial como las redes sociales de

\footnotetext{
2 Archivo de La Paz (ALP), Cajas Reales (CR), 1616-1624 Caja 2 Documento 6 (en adelante, $\mathrm{RNH}$ ). Salvo indicación de lo contrario, todas las referencias documentales corresponden a este expediente.
} 
relacionamiento (ver Cuadro 1 y Mapa 1). Entendemos que esta estrategia narrativa facilitará el seguimiento del proceso. En el balance final retomamos los interrogantes aquí presentados y esbozamos posibles derivaciones.

\section{Cuadro 1. Esquema general del pleito contra el capitán Martín Navarro de Hinojosa, corregidor de Paucarcolla}

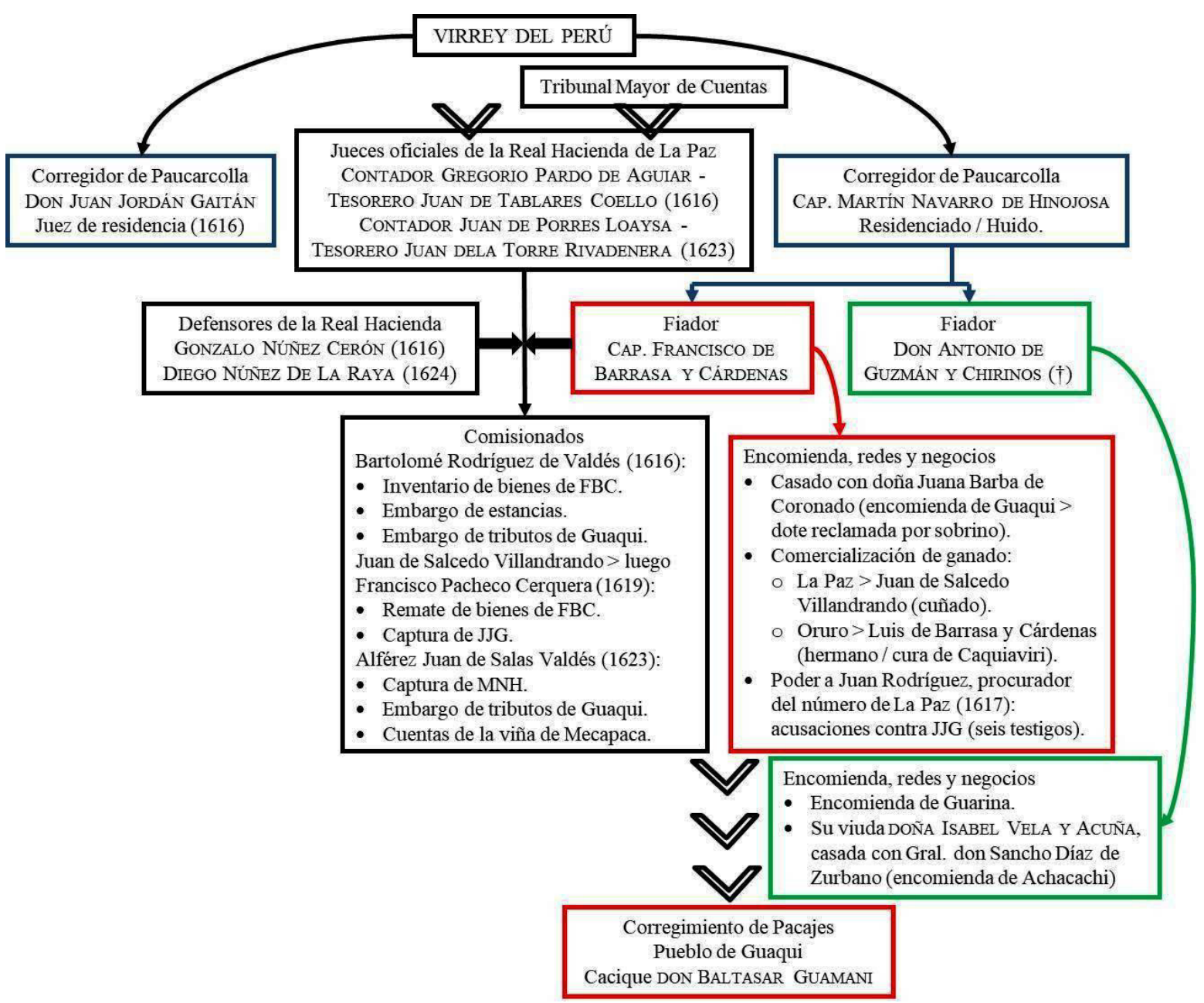




\section{Mapa 1. Derroteros del corregidor Martín Navarro de Hinojosa}

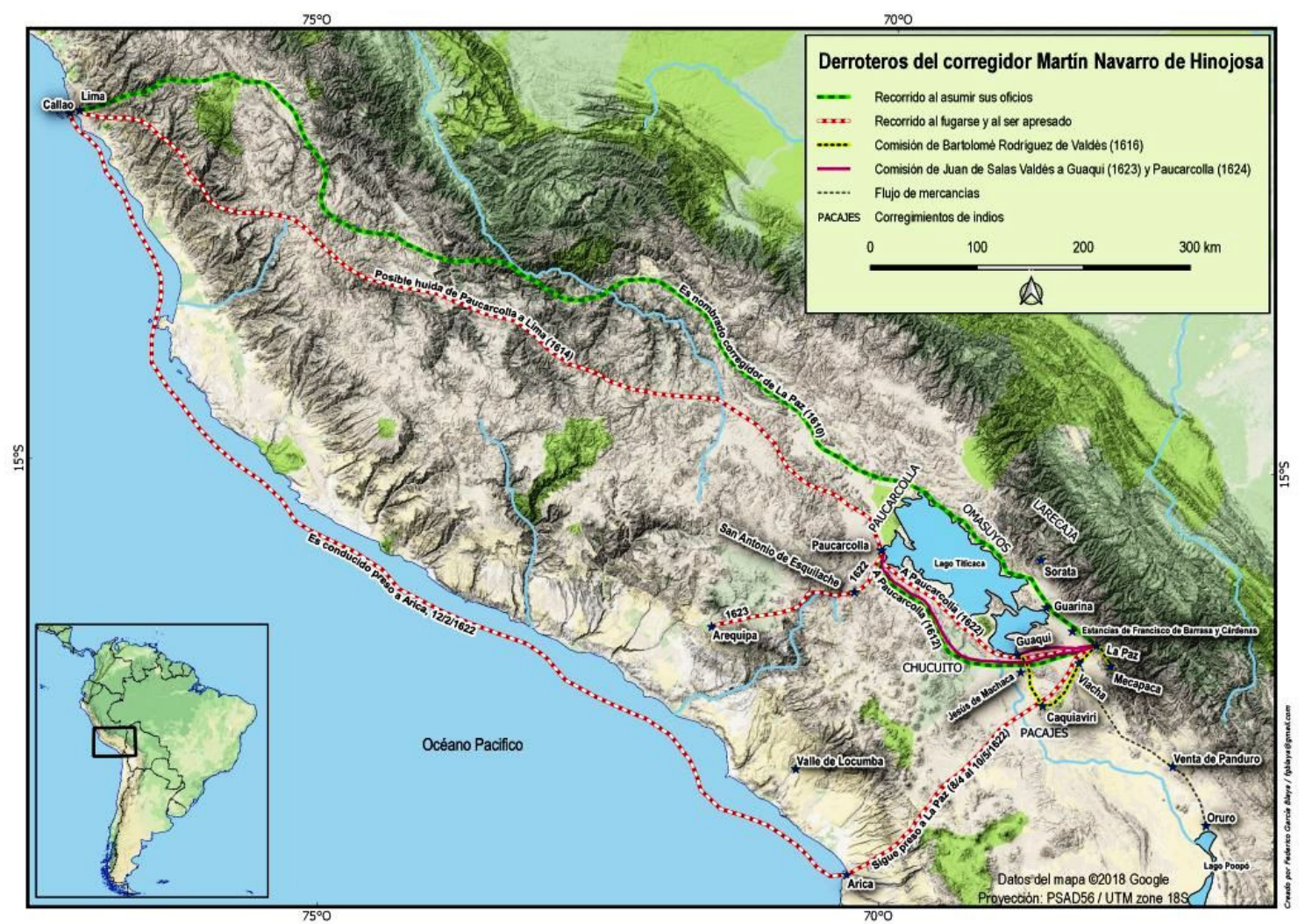

\section{Episodio 1. A corregidor huido, residencia frustrada (1616)}

El 11 de julio de 1616, don Suero Vigil de Quiñones, corregidor de La Paz, recibió de manos del don Juan Jordán Gaitán, flamante corregidor de Paucarcolla, la provisión otorgada en octubre de 1614 por el virrey don Juan de Mendoza y Luna, marqués de Montesclaros, en la que lo designaba como juez de residencia de su antecesor, el capitán Martín Navarro de Hinojosa (16121614), y de sus fiadores, el capitán Francisco de Barrasa y Cárdenas y los herederos de don Antonio de Guzmán y Chirinos. Según lo establecido por la legislación, Gaitán tenía un plazo de treinta días para auditar las cuentas dejadas por Hinojosa, a la sazón huido y de desconocido paradero. Ante semejante escándalo, Vigil de Quiñones optó por eludir la responsabilidad de dar curso a la provisión, aduciendo que la misma no competía a su jurisdicción, por lo cual Gaitán acudió los oficiales de la Real Hacienda, ante quienes los fiadores se habían sometido especialmente en la escritura de fianza. En efecto, el contador Gregorio Pardo de Aguiar y el tesorero Juan de Tablares Coello, oficiales de la Real Hacienda de la ciudad, revisaron los cargos, descargos y alcances imputados al prófugo corregidor Hinojosa por los tributos de los repartimientos que componían el corregimiento. El ajuste de cuentas arrojó una deuda de más de 10.000 pesos ensayados, de los cuales solo se habían 
recuperado 310 pesos. $^{3}$ Dado que Hinojosa se encontraba prófugo tras haber sido inicialmente apresado por tal incumplimiento, Gaitán exhortó a los oficiales para que procedieran contra los fiadores del corregidor, ejecutando sus bienes. $^{4}$

En el acto, los oficiales ordenaron trasladar las cuentas tomadas a Hinojosa. El alcance total estaba compuesto por los 8.828 pesos y 4 tomines de plata ensayada, a lo cual se agregaban 3296 pesos 2 tomines y 11 granos de oro en polvo, 400 hechuras de ropa de abasca, 60 fanegas de chuñu y 136 arrobas de pescado (que equivalían a 1.347 pesos y 5 tomines ensayados, aproximadamente). Hinojosa había alegado no poseer más recursos, aunque sí reconocía que el contador le debía 200 pesos corrientes y Diego Guerrero de Leyva otros 650 pesos.

Hasta aquí, el proemio del caso. La huída de un corregidor ante la inminencia de su residencia y con las cuentas sin saldar activó los mecanismos de la fiscalidad colonial para enmendar el escandaloso acontecimiento. ¿A dónde habría escapado Hinojosa?

\section{Flashback. Biografía de un corregidor itinerante}

Nacido hacia 1561 en la Villa de San Clemente (La Mancha), el capitán Martín Navarro de Hinojosa era hijo de Martín Navarro de Torres y de doña María de Hinojosa. Junto a su hermano mellizo Juan de Hinojosa pasaron al Perú en sus años de juventud, de donde regresaron en 1590 acompañando a su prima hermana, doña Gerónima de Hinojosa, quien debía tratar negocios en Madrid. Partieron de La Habana en la nao del maestre Juan Pérez de Portu, pero un naufragio en las islas Azores provocó la pérdida de sus bienes y de la licencia que autorizaba su traslado. Esto motivó que los hermanos Hinojosa debieran tramitar nuevos permisos para retornar, los cuales fueron concedidos por Real Cédula del 21 de enero de 1591 y por licencia de la Casa de Contratación del 30 de enero de 1592. ${ }^{5}$ Para septiembre de 1598 lo encontramos en La Paz como

\footnotetext{
${ }^{3} \mathrm{RNH}$, ff. 9r-24v. Los 310 pesos ensayados se componen de "tres mulas y el macho en 240 pesos, y las seis botijas de vino a 6 pesos cada una, y la silla de brida en 20 pesos, los dos bufetes viejos en 12 pesos, un fuste viejo ginete en 2 pesos", bienes rematados el 17 de septiembre de 1615 en favor del Licenciado Bartolomé Ortíz de Guzmán, cura del pueblo de San Juan Bautista de Puno (RNH, f. 29r).

4 "Y que la fianza, que para esto dan, es tan poderosa, que por los mesmos autos, que se hicieren con el residenciado, se puede proceder contra su fiador, y ponerle en la Carcel, aunque sea noble, como pudiera ser puesto el principal: porque estas deudas descienden de delito" (Solórzano Pereira 1739 [1629]: Libro V, cap. 2, § 21; 2: 265).

5 Archivo General de Indias (AGI, Sevilla) Indiferente General 2098, N. 168; AGI Casa de Contratación 5236, N. 2 R. 26. El naufragio ocurrió durante el "trienio negro" de la navegación española a Indias (1598-1591), en pleno contexto de la guerra contra Inglaterra (Pérez-Mallaína Bueno 1997: 84-85).
} 
apoderado del mercader Juan de Arteaga para la cobranza de un esclavo por 570 pesos corrientes, mientras que entre 1605 y 1609 fue corregidor de Huarochirí, designado por el virrey don Gaspar de Zúñiga y Acevedo, conde de Monterrey. ${ }^{6}$

Entre junio y diciembre de 1610, como corregidor de La Paz designado por el virrey marqués de Montesclaros, Navarro de Hinojosa protocolizó cinco escrituras públicas que revelan tanto la adquisición de llamas y otros "géneros de la tierra" para su comercialización (a pesar de no encontrarse facultado para negocios particulares) como sus vinculaciones con los caciques de los pueblos de Guaqui, Caquiaviri, San Andrés y Jesús de Machaca (corregimiento de Pacajes). ${ }^{7}$ Destaca una sexta escritura, fechada el 24 de noviembre de ese año, por la cual el corregidor cobró 778 pesos y 4 tomines ensayados del contador Gregorio Pardo y del tesorero don Juan Cortina de Montalvo, oficiales de la Real Hacienda, a cuenta de su salario. ${ }^{8}$

Tal como vimos, dos años después Hinojosa obtuvo del mismo virrey marqués de Montesclaros el nombramiento como corregidor de Paucarcolla, en reemplazo de don Alonso Fernández Marmolejo, designación que probablemente respondiera a su experiencia previa en La Paz. Reingresaba así en el escenario político paceño (si acaso alguna vez lo abandonó). En abril de 1613 solicitó al Tribunal Mayor de Cuentas de Lima una certificación donde constara hallarse libre de deudas, la cual fue concedida y remitida a los oficiales de la Real Hacienda de La Paz en junio de ese año. El corregidor se excusaba por la demora en el envío de la certificación aduciendo un inesperado viaje al Cuzco. Estaba preocupado por conocer si los oficiales reales habían recibido las remesas de plata correspondientes a los repartimientos a su cargo, enviadas mediante una libranza otorgada a Rodrigo de Meseta, quien debía entregarla en La Paz a Antonio de Soto para, a su vez, ser enteradas en la Caja Real. Solicitaba, asimismo, información sobre el resultado del remate de los bienes tributados. ${ }^{9}$

Desconocemos si la plata y los bienes remitidos por Hinojosa a los oficiales de la Real Hacienda de La Paz efectivamente llegaron a destino. Si los intermediarios desviaron ese dinero, el corregidor pudo haber denunciado la situación, lo cual tampoco consta en la documentación. Si bien en junio de 1613

\footnotetext{
${ }^{6}$ Archivo Histórico Municipal (AHM, La Paz), Registros de Escrituras (RE) 1, ff. 64v-65v: Gaspar de Chavez. El título de corregidor de Huarochirí en Lee y Bromley 1935-1962: 14, 9961001 (agradecemos a Mónica Medelius la copia digital de este registro). Cf. Acosta 2014 (1979): 362; AHM RE 2, f. 389v: Sebastián de Córdova.

7 AHM RE 2, ff. 148r-153v, 162r-162v, 177v-178v, 271v-272r y 408v-409r: Sebastian de Córdova. Biblioteca Central de la Universidad Mayor de San Andrés (BCUMSA, La Paz), Manuscrito 62, ff. $1 r-3 r$.

${ }^{8}$ AHM RE 2, ff. 389r-390v.

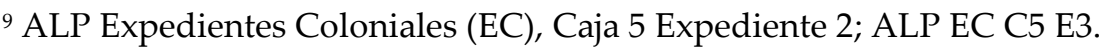


no registraba deuda alguna en el Tribunal Mayor de Cuentas, para agosto de 1615 fue alcanzado en sumas exorbitantes correspondientes a los tercios de Navidad de 1612, San Juan y Navidad de 1613 y San Juan de 1614, lo cual contradecía la certificación expedida. Esta situación, por demás confusa, motivó la intervención de don Juan Jordán Gaitán, poniendo en marcha el protocolo de la residencia.

\section{Episodio 2. El reverso de la confianza (1616-1617)}

Vencido el plazo de la residencia, en septiembre de 1616 el defensor de la Real Hacienda, Gonzalo Núñez Cerón, solicitó a los jueces exigieran a los fiadores saldar la deuda, dado que Hinojosa continuaba prófugo. El defensor nombró a Diego de Andrada, teniente de aguacil, para ejecutar las fianzas, previa confección del inventario de los bienes de cada fiador.

¿Quiénes eran los fiadores del corregidor Hinojosa? El capitán Francisco de Barrasa y Cárdenas y don Antonio de Guzmán y Chirinos pertenecían al núcleo de la elite paceña (López Beltrán, 1998; Morrone, 2012; García Guzmán, 2014). Natural de Escalona (Toledo), Barrasa había pasado al Perú como criado del virrey Toledo, con el grado de capitán de guardia de camarín mayor. Como su "hombre de confianza" (Levillier, 1935: I, 205), asistiría al virrey durante su visita general, en las campañas contra los "incas rebeldes" de Vilcabamba y los chiriguanos, en la recolección del "servicio gracioso" para la guerra contra el imperio otomano y en el proceso de reducción a pueblos de indios en los alrededores de Potosí. Acompañó al virrey a Arequipa y a Lima, donde participó de la defensa del puerto del Callao contra las amenazas de Francis Drake, a quien persiguió hasta Tierra Firme. Su fidelidad al virrey Toledo lo llevó de retorno a la península, donde posteriormente condujo ocho compañías de infantería bajo el mando de don Juan Gaspar Fernández Pacheco, V duque de Escalona, en la jornada portuguesa de la guerra anglo-española, y luego en Francia. ${ }^{10}$

Durante su estancia en Lima, Barrasa había otorgado en mayo de 1578 una escritura de dote en favor de doña Juana Barba de Coronado, hija y heredera del capitán Hernando Coronado, encomendero de Guaqui hurinsaya (ver Cuadro 2). ${ }^{11} \mathrm{~A}$ través de este matrimonio, ingresaría en las redes de poder

\footnotetext{
${ }_{10}$ ALP Registros de Escrituras (RE) C14 L20, ff. 631r-634v: Gaspar de Chaves.

${ }^{11} \mathrm{RNH}$, ff. 96v-102v. Según la visita toledana, el repartimiento de Guaqui contaba con un total de 1.280 tributarios, de los cuales 650 fueron registrados como aymara (pastores) y otros 630 como uru (pescadores). Los primeros debían pagar un tributo anual compuesto de 3412 pesos ensayados, 100 piezas de ropa de abasca, 130 llamas y 120 fanegas de chuñu, mientras que los segundos pagarían 1.890 pesos ensayados, 200 arrobas de pescado y 210 hechuras de ropa. Restados los 2.702 pesos ensayados imputados al pago del sínodo de los curas doctrineros y salarios de justicias y caciques, quedaban libres de costas 2.600 pesos ensayados y la totalidad
} 
de la elite paceña; un típico enlace entre un afamado militar peninsular y la heredera de una rica encomienda peruana, hija de un "benemérito de la conquista" (Presta, 1997).

Cuadro 2. Redes de parentesco del capitán Francisco de Barrasa y Cárdenas en la elite paceña

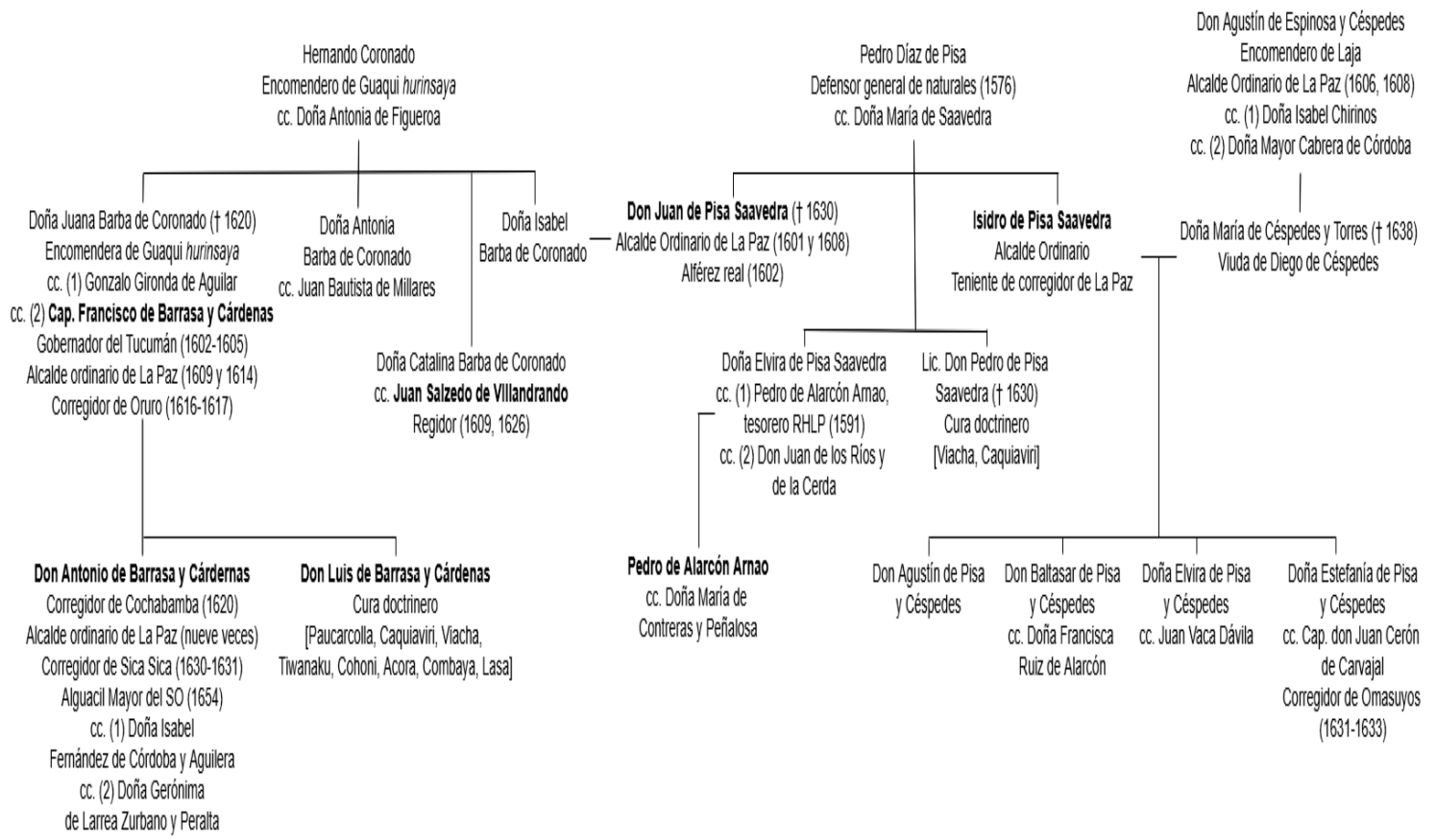

De regreso en La Paz, en febrero de 1598 concertó con Gerónimo Osorio, mestizo natural de Cochabamba, la asistencia para la explotación de la estancia ganadera de Copaquira, ubicada a una legua al sudeste de Guaqui, durante un año. ${ }^{12}$ Perfilaba así el inicio de una empresa productiva que combinaría la cría de ganado autóctono y europeo (cuyo objetivo era la obtención de lana para su comercialización) con los réditos de la encomienda de Guaqui (Presta, 2000: 136-138).

Años más tarde, el virrey don Luis de Velasco lo nombraría gobernador del Tucumán, oficio que ejerció entre 1602 y 1605 (Glave, 1998: 76-83, 2007;

de los rubros en especies, que debían repartirse por mitades entre los encomenderos de ambas parcialidades (Cook 1975: 54).

${ }^{12}$ AHM RE 1, ff. 89v-90v: Gaspar de Chaves. 
Castro Olañeta, 2013). Nuevamente en La Paz, continuaría profundizando su perfil empresarial. Por un lado, en 1606 compró a Pedro Meléndez Valdés y su esposa, doña Agustina de Zúñiga, la estancia de Anta Axarana, ubicada a cuatro leguas de la ciudad, sobre el camino a Guarina, provista de más de 100 cabezas de ganado vacuno, casas de yanaconas y un pastor natural del pueblo de Laja, por 2.200 pesos corrientes; por el otro, compró a Juan de Tablares Coello y su esposa, doña Gregoria de Rabanal, una viña en Mecapaca, a otras cuatro leguas valle abajo de la ciudad, dotada de una viña, una bodega, una casa y huertas de árboles frutales. ${ }^{13}$

La combinación de los réditos procedidos de la encomienda de Guaqui y de sus propiedades rurales, emplazadas tanto en la puna como en el valle bajo de La Paz, sumada a su trayectoria política y sus vínculos con el poder virreinal, posicionó al capitán Barrasa entre las primeras líneas de la elite paceña. Encomienda, estancias y servicios constituyeron una plataforma de impulso hacia la faceta de hombre de negocios, toda vez que los bienes tributados por los indígenas de Guaqui y los obtenidos por la explotación de sus estancias agroganaderas serían comercializados en las ciudades de La Paz y Potosí y en la recientemente fundada Villa de San Felipe de Austria de Oruro. A su vez, este perfil redundó en una acumulación progresiva de capital social (materializado en sus recurrentes apariciones en los protocolos notariales como testigo, poderdante y fiador) y político (fue alcalde ordinario en 1609 y 1614 y corregidor de Oruro en 1616-1617).

Poco sabemos, en cambio, sobre el segundo fiador. Don Antonio de Guzmán y Chirinos era hijo y heredero de Cosme de Guzmán, encomendero de Guarina hurinsaya, y de doña Ana Chirinos de Pernía, perteneciente a la familia encomendera de Pucarani hanansaya. Como veremos, su viuda doña Isabel Vela y Acuña debió enfrentar el intento de ejecución del patrimonio familiar por parte de la Real Hacienda, específicamente de la chacra de Moyobaya en términos del pueblo de Sorata (corregimiento de Larecaja), ciertos objetos de plata labrada y los réditos del repartimiento de Guarina hurinsaya. ${ }^{14}$

${ }^{13}$ ALP RE C7 L11, s/f: Gaspar de Chaves; C11 L15, ff. 33-6v: Sebastian de Córdova; RNH, ff. 51v$52 \mathrm{v}$.

${ }_{14} \mathrm{RNH}$, f. 40r. El repartimiento de Guaqui contaba con un total de 1.413 tributarios, de los cuales 972 fueron registrados como aymara (pastores) y otros 440 como uru (pescadores). Los primeros debían pagar un tributo anual compuesto de 2.675 pesos y 4 tomines de plata ensayada, 1.946 pesos de oro quintado, 200 piezas de ropa de abasca, 200 hechuras de ropa, 250 fanegas de chuñu y otras 250 de maíz, mientras que los segundos pagarían 1100 pesos ensayados, 55 fanegas de chuñu, 150 hechuras de ropa, 200 costales y 200 arrobas de pescado. Restados los 2.957 pesos ensayados imputados al pago del sínodo de los curas doctrineros y salarios de justicias y caciques, quedaban libres de costas 818 pesos y 4 tomines de plata ensayada y la totalidad de los rubros en oro y especies, que debían repartirse por mitades entre los encomenderos de ambas parcialidades (Cook 1975: 52-53). La ejecución de los bienes de 
En efecto, ambos fiadores eran renombrados vecinos de la elite local, miembros de familias encomenderas y hombres de negocios con un claro perfil terrateniente y comerciante (ver Mapa 2). En clave de reproducción del capital social, resultaba lógico que otorgaran sus fianzas en favor de quien pocos años atrás fuera corregidor de La Paz, y con quien probablemente hayan entablado vínculos mercantiles. Siguiendo el procedimiento habitual, los fiadores ofrecieron en garantía sus propiedades rurales, sin sospechar siquiera el embarazoso acontecer de los hechos que sobrevendrían.

\section{Mapa 2. El espacio de los fiadores ejecutados}

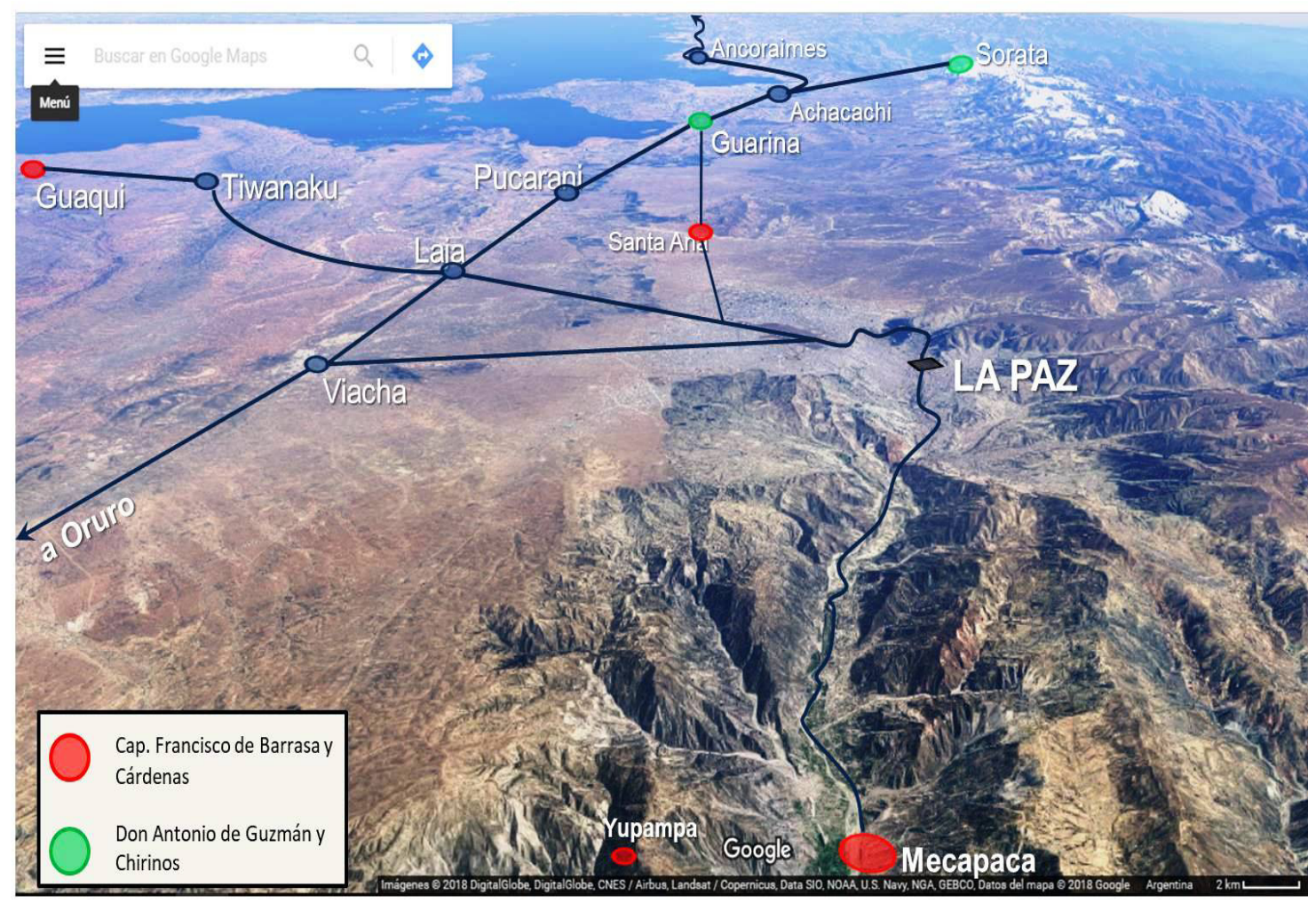

Entre septiembre y octubre de 1616 se sucedieron las averiguaciones en torno a la eventual ejecución de sus bienes. Para la confección del inventario y la posterior ejecución sobre Barrasa y Cárdenas, los oficiales reales comisionaron a Bartolomé Rodríguez de Valdés, quien encabezaría una comitiva compuesta por dos alguaciles y cuatro autoridades étnicas de las parroquias de San Sebastián y Santa Bárbara de la ciudad de La Paz. Conocedores de la lengua y de la espacialidad nativas, ellos serían los

Guzmán y Chirinos fue posteriormente apelada por el segundo marido de su viuda (RNH, ff. 222r-222v). 
encargados de interactuar con los mayordomos de las estancias y de recolectar el ganado y todos aquellos bienes que pudieran ser rematados en pública almoneda.

El 26 de septiembre la comitiva llegó a la estancia de Santa Ana (también llamada Yrucunga). Gracias a los testimonios del yanacona Hernando Acnota y del khipucamayoq Agustín Laura, Rodríguez de Valdés pudo averiguar que, por orden del fiador, su hermano don Luis de Barrasa y Cárdenas, cura de Caquiaviri, había retirado hacía dos meses alrededor de 200 cabezas de ganado para venderlas en la recientemente habilitada plaza mercantil de Oruro. ${ }^{15} \mathrm{~A}$ pesar de ello, Rodríguez de Valdés recolectó en los días posteriores el ganado disponible y otros bienes, tanto de la estancia de Yrucunga como de la de Andacarani; a los pocos días, hizo lo propio en la chacara de Yuyupampa, en el valle de Mecapaca. ${ }^{16}$

La comitiva embargadora regresó a La Paz para continuar su camino por Viacha y Caquiaviri, donde Rodríguez de Valdés debería entrevistarse con el corregidor de Pacajes para ejecutar los réditos del repartimiento de Guaqui hurinsaya. Ante la ausencia del funcionario, el 5 de octubre el comisario llegó a Guaqui y convocó a sus caciques para iniciar el embargo. Con la asistencia del khipucamayoq o "contador", el cacique principal don Baltasar Guamani dio cuenta de las tasas que ya pagadas al encomendero, aduciendo que nada debían al real erario. No contento con este testimonio, Rodríguez de Valdés indicó a los caciques no pagar los siguientes tributos hasta que los oficiales de la Real Hacienda lo ordenaran. Asimismo, exhortó al teniente de corregidor para que informara lo que efectivamente tenían pagado los tributarios de Guaqui; el teniente se desligó de toda responsabilidad sobre la cobranza de tributos, aduciendo no competerle tal causa.

Entre tanto, el contador Pardo emitió otro auto donde reconocía que Barrasa y Cárdenas poseía más ganado del declarado. Al parecer, un mayordomo de Juan de Salcedo Villandrando, cuñado de Barrasa, había trasladado ganado de la estancia del fiador a la carnicería de la ciudad; en

${ }^{15}$ Esto cobra sentido si recordamos que, a la sazón, Barrasa y Cárdenas era corregidor de Oruro (ALP RE C14 L20, ff. 637v-638r: Gaspar de Chávez) y que su hermano el cura de Caquiaviri era su principal operador mercantil (Morrone, 2013a: 38-43).

16 Si bien en el documento la estancia es denominada Andacarani (f. 50r) o Anda Acarani (f. 50v), se trata en realidad de la ya mencionada estancia de Anta Axarana. La misma se ubicaba "junto al camino real que ba desta çiudad al pueblo de Guarina", a cuatro leguas de la ciudad $(22,3 \mathrm{~km})$ y muy próxima de la estancia Santa Ana. A principios de 1613, Barrasa y Cárdenas había hipotecado tanto la estancia de Anta Axarana como la viña de Mecapaca como garantía en una obligación de pago en favor de Pedro de Ibarra, tesorero de la Real Hacienda, por 2024 pesos corrientes; asimismo, impuso un censo de 35 pesos corrientes anuales (por 700 de principal) en favor del convento mercedario de La Paz (ALP RE C11 L15, ff. 3r-6v y 103r-107v: Sebastián de Córdova). Por otro lado, ubicamos el actual topónimo Yupampa a 5,4 km (una legua) al sudeste de la población de Mecapaca. 
efecto, el carnicero fue llamado a testificar y se revisaron las marcas de hierro del ganado secuestrado en la carnicería. ${ }^{17}$ En vista de tan burdo intento de defraudación, el defensor de la Real Hacienda solicitó el 10 de octubre la inmediata emisión del albalá de almoneda para rematar los bienes de Barrasa; tres días después, se ejecutaron por un total de 3600 pesos corrientes.

Sin embargo, el 17 de ese mes el contador Pardo notificó al comisionado sobre una nueva solicitud del defensor de la Real Hacienda para realizar otra inspección de la estancia de Santa Ana, dado que sospechaba había mayor cantidad de bienes. Efectivamente, al recorrer los confines de la estancia, los yanaconas enviados por Rodríguez de Valdés hallaron 286 nuevas cabezas de ganado. Pardo autorizó el remate de ese ganado para pagar de su procedido los 96 pesos corrientes que correspondían al salario del comisionado.

Cuando este tramo del proceso parecía cerrarse, el 24 de octubre don Pedro de Alarcón Arnao, sobrino de Barrasa y Cárdenas, cuestionó la ejecución de los bienes aduciendo (como era frecuente en esos casos) que formaban parte de la dote de la esposa del fiador, doña Juana Barba de Coronado, y que por ello no estaban afectados a la fianza firmada en favor del corregidor Martín Navarro de Hinojosa. Alarcón Arnao reclamaba esos bienes en tanto beneficiario de un censo otorgado por ambos esposos e imputado sobre una casa que estos habían comprado a los cuñados del fiador, don Juan de Pisa Saavedra y su esposa, doña Isabel Barba de Coronado. En los primeros días de noviembre de 1616 el defensor de la Real Hacienda solicitó a los oficiales reales no admitir la oposición impuesta por Alarcón Arnao. Por su parte, el beneficiario del remate exigió la entrega de los bienes ejecutados, aunque no fue el único preocupado: Isidro de Pisa Saavedra solicitó al corregidor de La Paz un traslado de la escritura de tutela y curaduría que tenía sobre su sobrino don Pedro de Alarcón Arnao, mientras que doña Juana Barba de Coronado presentó su escritura de dote para reclamar la devolución los bienes ejecutados. ${ }^{18}$

De cualquier modo, para febrero de 1617, el defensor de la Real Hacienda solicitó a los oficiales reales dieran celeridad a los trámites necesarios para ejecutar las fianzas, siguiendo órdenes del virrey don Francisco de Borja y Aragón, príncipe de Esquilache. La urgencia de este pedido radicaba en que el

\footnotetext{
17 El misterio del ganado secuestrado recién se resolvería el 18 de enero de 1617, cuando el carnicero se presentó ante el alcalde del cabildo paceño afirmando que Rodríguez de Valdés vendió las 32 vacas que deberían haberse rematado (RNH, ff. 103r-103v).

18 Si bien doña Juana Barba de Coronado comisionó a sus cuñados Juan de Salcedo Villandrando (esposo de su hermana doña Catalina) y don Juan de Pisa Saavedra (esposo de su hermana doña Isabel) y al defensor de la Real Hacienda para que soliciten su carta de dote el 7 de noviembre de 1616, por algún motivo que desconocemos esta actuación no se realizó sino hasta el 16 de enero de 1620, cuando doña Juana volvió a pedir un traslado de la carta ante los nuevos oficiales de la Real Hacienda. Ver Cuadro 2.
} 
defensor tenía la certeza de que el prófugo corregidor Hinojosa se hallaba en Lima.

Este segmento de la narrativa muestra la densidad de la red de relaciones familiares y de negocios tramada por la elite paceña de inicios del siglo XVII. La notabilidad y la gravitación del fiador en el escenario político local activaron una serie de estrategias de reacomodamiento ante la amenaza de ejecución la fianza, amenaza que sacudió de lleno la trama de la red, para evitar la pérdida de un patrimonio consolidado y acrecentado desde los primeros tiempos de la encomienda. La topografía de la red incluía encomenderos y miembros del cabildo paceño, unidos por inmediatos vínculos de parentesco a través de los cuales articulaban negocios en espacio surandino. Asimismo, observamos los denodados esfuerzos de los oficiales de la Real Hacienda para dar con los bienes de los fiadores y cumplimentar con las exigencias de las instancias superiores de gobierno, aunque tal urgencia también podía obedecer a conflictos intraelite de compleja dilucidación. Finalmente, el hecho de que el corregidor Hinojosa haya sido encontrado en Lima sugiere un recurso a sus propias redes extra-regionales, que databan de sus turbulentos años mozos, previos a su inserción en el escenario paceño hacia 1610.

\section{Episodio 3. La resistencia de los fiadores (1617)}

El embargo de los tributos del repartimiento de Guaqui desató una escalada inusitada en los niveles de la conflictividad. La contraofensiva de los fiadores no se hizo esperar. En abril de 1617, Isidro de Pisa Saavedra desafió la autoridad de los oficiales reales en plena plaza pública de la ciudad, diciendo "que lo que contenia el dicho auto heran disparates", mientras que don Pedro de Alarcón Arnao confrontó al contador Pardo declamando "otras palabras colericas enpuñandose en la espada y daga para el dicho contador y el dicho Ysidro de Pisa tanbien segunda vez torno a tratar otras palabras desconpuestas". Don Antonio de Barrasa y Cárdenas (hijo y apoderado del fiador, a la sazón alcalde ordinario) respaldó a sus parientes y envió preso al contador Pardo "diziendo palabras de mucha colera perdiendonos el respeto que se nos deve como a vuestros juezes ofiçiales reales amenaçandonos que nos havia de meter en un cepo y trato de ponerlo por obra alborotando esta republica". ${ }^{19}$ Tal fue la reacción de la trama parental en la defensa corporativa ante el intento de incautación por parte de los oficiales reales. Irían aún más allá.

En marzo, Barrasa y Cárdenas otorgó un poder a favor de su hijo don Antonio para que lo representase ante los jueces oficiales reales en todo lo concerniente a la ejecución de sus bienes. A las pocas semanas, el apoderado

${ }^{19}$ ALP EC C5 E28, f. 1 r. 
sustituyó el poder en Juan Rodríguez, procurador del número de la ciudad, quien a partir del mes de julio alegaría de manera enfática contra de la ejecución y el accionar de los oficiales reales. En efecto, Rodríguez desconoció la ejecución y argumentó que el corregidor Hinojosa efectivamente había pagado lo adeudado a su sucesor, don Juan Jordán Gaitán, pero que este sospechosamente no hizo caso del pago, ejecutando tan solo "un baul biejo y unas mulas de que se presume con evidençia que fue algun pacto y colusion entre los susodichos". ${ }^{20}$

Natural de Simancas y vecino la ciudad de Valladolid, don Juan Jordán Gaitán era hijo del Licenciado Pedro Jordán, oficial de la Inquisición, y de doña Catalina Gaitán. En mayo de 1603 había solicitado ante el Consejo de Indias el paso a la Nueva España con el objetivo de reclamar la herencia de dos parientes suyos fallecidos sin hijos. ${ }^{21}$ De hecho, lo hallamos dos meses después entre los criados que acompañaron al virrey marqués de Montesclaros, al embarcar en la nao Almiranta hacia la Nueva España. ${ }^{22}$

Para sustentar la causa del fiador Barrasa y Cárdenas, su apoderado Juan Rodríguez ofreció la información de seis testigos. Todos coincidieron en que Gaitán, supuestamente a cargo de auditar las cuentas de Hinojosa, no había entregado los alcances a los oficiales de la Real Hacienda "y despues no hizo diligencia en cobrar la dicha cantidad por hazer carga en los fiadores y librar al dicho prinçipal y el tal fraude y engaño". ${ }^{23}$ Asimismo, señalaron que Gaitán había permitido que un sobrino de Hinojosa llevara más de 1.000 botijas de vino que el corregidor había comprado en valle de Locumba (avaluadas en más de 14.000 pesos corrientes) y más de 600 llamas a Oruro para su comercialización, dejando finalmente libre a Hinojosa para que huyera del pueblo de San Martín de Paucarcolla hacia Lima. Otro testigo indicó que Gaitán había exhortado a Hinojosa a no entregar los alcances a los oficiales de la Real Hacienda. Mientras los testigos daban sus informaciones, el defensor de la Real Hacienda solicitó nuevamente el embargo y remate de los bienes de Barrasa y Cárdenas, como así

\footnotetext{
${ }^{20}$ RNH, f. 111v.

${ }^{21}$ AGI México 224, N. 23. Su hermano don Antonio Jordán Gaitán pasó al Perú antes de 1608, probablemente siguiendo su camino (Sanz 1995: 334). Para 1640, don Juan Jordán Gaitán y su esposa, doña Leonor de Tordoya, adeudaban más de 300 pesos corrientes a la cofradía del Santísimo Sacramento de la Catedral y al convento franciscano del Cuzco. Archivo Departamental del Cuzco, Fondo Cabildo, Legajo 4, Expediente 73. Don Antonio había sido bautizado en la iglesia de San Miguel y San Julián de Valladolid el 12 de septiembre de 1587, al igual que sus hermanos menores Gregorio Manuel (18 de mayo de 1595) y Manuela (12 de junio de 1597). Iglesia de Jesucristo de los Santos de los Últimos Días, Microfilm 1039197.

22 AGI Contratación 5273, N. 3, f. 3r. Cf. Latasa 2012: 58.

${ }^{23}$ RNH, f. 111 v.
} 
también la captura y prisión para el corregidor Gaitán. En efecto, el 27 de julio los jueces comisionaron para tales fines a Juan de Salcedo Villandrando. ${ }^{24}$

Evidentemente, aquello que inició como un juicio de residencia a un corregidor huido se volvió, en virtud de las presiones de los fiadores, en contra del residenciador por cohecho con el residenciado. Los alegatos contra el corregidor Gaitán complejizaron el panorama, toda vez que lo comprometían íntimamente aún durante la residencia de su antecesor, con quien supuestamente había concertado lucrativos negocios a través del "espacio del trajín" (Glave, 1989: 39-50). ${ }^{25}$ Debimos aguardar a que los fiadores vieran ejecutados sus bienes para que el peso de la carga se revirtiera en contra del nuevo corregidor, un "recién llegado" que pretendía abusivamente tensar al máximo las redes de la elite paceña.

\section{Episodio 4. Los oficiales reales en la encrucijada (1619-1620)}

En este punto, el expediente da un salto temporal. Recién el 25 de enero de 1619 (es decir, un año y medio después del último auto de la causa) los jueces oficiales reales designaron a Francisco Pacheco Cerquera para proseguir la comisión de Salcedo Villandrando. Sin perder más tiempo, Pacheco Cerquera se presentó en febrero de ese año ante el capitán Eugenio de Zamora, nuevo corregidor de Paucarcolla, para notificar a Gaitán lo proveído por los jueces. No solo Gaitán desconoció las acusaciones, sino que también protestó contra lo que entendía una intromisión de los oficiales reales en asuntos ajenos a su competencia. ${ }^{26}$ Asimismo, desestimó la información presentada por los testigos del fiador Barrasa y negó haber participado en la venta de los bienes de que se lo acusaba. Para mayor sustento de su propia causa, denunció que Salcedo Villandrando no debía ser juez comisionado por ser cuñado de su adversario. Pacheco Cerquera decidió no interceder, alegando no ser juez de la causa sino un mero comisionado.

Por su parte, el defensor de la Real Hacienda desestimó la protesta de Gaitán y recomendó a los jueces oficiales reales que fueran ellos mismos tras el rebelde corregidor. En este estado de situación, el 4 de febrero de 1620 Barrasa

\footnotetext{
${ }^{24}$ Más adelante, el 7 de agosto de ese año, el general don Antonio de Barrasa y Cárdenas solicitaría en nombre de su padre a los jueces suspendieran la comisión otorgada a Salcedo Villandrando porque este era cuñado y apoderado de su padre $\mathrm{y}$, como tal, parte interesada en la persecución del corregidor Gaitán (RNH, ff. 125r-155r).

${ }^{25}$ La residencia resultaba una "instancia de aprendizaje" sobre posibles negocios: "Ningún corregidor ocultaba a su sucesor tales ardides, a fin de tenerlo propicio en el curso del juicio de residencia; correlativamente, el heredero de aquellos trucos tendía un velo sobre los de su antecesor, a fin de que al descubrirse estos, no se le cegara a él también la fuente de ilícitos ingresos" (Lohmann Villena, 2001 [1957]: 488).

${ }^{26}$ Gaitán señaló que "siendo culpado el contador Gregorio Pardo en no aver rescevido fianças legas llanas y abonadas" (RNH, f. 157v).
} 
se presentó ante los jueces para dar por tierra los alegatos de Gaitán. Defendía la competencia de los oficiales de la Real Hacienda en la causa contra el corregidor, acusando a Gaitán de no haber embargado a Hinojosa cuando debió hacerlo y respaldando lo informado por los testigos presentados por su apoderado.

Este segmento de la causa revela una notoria debilidad por parte de los oficiales de la Real Hacienda de La Paz tanto para dar con el paradero del corregidor Hinojosa como para sostener los embargos de los bienes de los fiadores. Para 1619, ya ejercía en Paucarcolla un nuevo corregidor, mientras el manto de sospechas, denuncias y reclamos seguía cayendo sobre sus dos antecesores. ¿A qué factores obedecería esta debilidad? ¿Se trataría de una "debilidad estructural" que endémicamente minaba la administración de la Real Hacienda? ${ }^{27}$

\section{Episodio 5. El retorno del corregidor (1621-1623)}

Pasarían dos años antes de tener nuevas noticias. El 9 de febrero de 1622, el escribano del gobierno virreinal certificó que los oficiales reales de La Paz, tras agotar sus esfuerzos en el escenario local, habían solicitado a la Audiencia de Lima tomar cartas en el asunto para dar con el paradero del prófugo corregidor Martín Navarro de Hinojosa y garantizar su pronta remisión. En efecto, y posiblemente en virtud de dos autos emitidos por el supremo tribunal en enero y mayo de 1621, Hinojosa fue hallado y enviado de regreso a La Paz, embarcándose desde el Callao hacia el puerto de San Marcos de Arica (ver Mapa 1). El capitán del galeón informó en abril de 1622 que traía preso a Hinojosa, y lo entregó al corregidor de la ciudad, quien a su vez lo envió hacia La Paz bajo la custodia de un arriero. En efecto, el 10 de mayo de 1622 Hinojosa fue confinado en la casa de la cofradía de Nuestra Señora del Rosario por hallarse enfermo, donde diariamente recibiría a una persona designada por los jueces oficiales reales para efectuar el ajuste de sus cuentas; al parecer, Hinojosa se manifestaba bien predispuesto a colaborar. ¿Pertenecía Hinojosa a la cofradía del Rosario? ¿Qué tipo de vínculos pudo haber entablado con otros cofrades? Su prisión en una casa de la cofradía, ¿no representaba una invitación para una nueva huida?

\footnotetext{
27 "El expediente de repetir contra los fiadores del insolvente demostró ser ineficaz, pues solía ocurrir que los garantes carecían de respaldo o incoaban pleitos para descargarse de la responsabilidad que subsidiariamente gravitaba sobre ellos a causa de la malversación del corregidor que los había presentado" (Lohmann, 2001 [1957]: 328).
} 
Episodio 6. Entre la prisión de los caciques y las presiones del virrey (16231624)

En mayo de 1622, Hinojosa se hallaba en La Paz; los jueces oficiales reales finalmente harían justicia sobre el escandaloso corregidor, a ocho años de expirado su oficio. El ciclo procesal parecía llegar a su fin, mas no fue así. El 12 de junio de 1623 los nuevos oficiales de la Real Hacienda, el contador Juan de Porres Loaysa y el tesorero Juan de la Torre Rivedeneyra, recibieron una severa advertencia dimanada del contador mayor Alonso Martínez de Pastrana, juez visitador de las Reales Cajas. Pastrana conminaba a los oficiales reales a cobrar los alcances aún adeudados por Hinojosa, quien nuevamente se hallaba prófugo, esta vez en el corregimiento de Paucarcolla. A pesar de la celeridad exigida por la superioridad, recién en diciembre de ese año los oficiales reales despacharon comisión al alférez Juan de Salas Valdés para traer preso a Hinojosa y cobrar nuevamente tributos embargados del repartimiento de Guaqui; en paralelo, exigían al mayordomo de la viña de Mecapaca presentar las cuentas de lo procedido en los últimos años. El proceso volvía a fojas cero. Se trataba, pues, de un nuevo avance sobre los fiadores del corregidor, en gran medida para compensar la imposibilidad de controlar al reincidente prófugo y para enfrentar, al mismo tiempo, las presiones de la Contaduría Mayor.

Nuevamente, don Baltasar Guamani, cacique principal de Guaqui, se negó el 28 de diciembre a pagar lo ya pagado. Salas Valdés le otorgó un plazo de doce días para defender su causa. En efecto, el 9 de enero de 1624 los caciques de Guaqui, presos en La Paz, presentaron las cartas de pago correspondientes a los tercios de 1616 y 1617, donde constaba el entero de los respectivos tributos del tiempo de vigencia de la fianza de su encomendero, de quien también presentaron un recibo de pago otorgado el 18 de enero de 1620 . El hilo de la justicia se cortaba por su segmento más delgado: resultaba mucho más accesible traer presos a los caciques de Guaqui que a un corregidor dos veces prófugo en virtud de su inserción en las tramas relacionales a escala interregional.

Mientras los caciques de Guaqui alegaban su justicia en La Paz, el alférez Salas Valdés ya había partido hacia Paucarcolla, donde tuvo noticia que Hinojosa había huido en 1622 al asiento de minas de San Antonio de Esquilache y, desde allí, a Arequipa en 1623, bajo el amparo de un hijo suyo, un fraile dominico que oficiaba como cura doctrinero de en esa diócesis. Nuevamente, Hinojosa había recurrido en sus redes (familiares, en este caso) para disuadir a los emisarios de la justicia real.

Visto lo informado por el alférez, el $1^{\text {o }}$ de febrero los oficiales reales emitieron un auto remitiendo todo el proceso a la corte de Lima. El 4 de noviembre recibieron por respuesta una provisión del virrey don Diego Fernández de Córdoba, marqués de Guadalcázar, en la que los exhortaba a 
inventariar los bienes del general don Antonio Barrasa de Cárdenas (específicamente, los réditos procedidos de la viña de Mecapaca) y de la viuda del segundo fiador, don Antonio de Guzmán Chirinos (al parecer olvidados por los oficiales reales). Este tramo de la secuencia procesal revela una nueva escalada: si los oficiales reales ya habían recibido una directiva del contador mayor, en el momento en que intentaron deshacerse de una causa que ya llevaba más de diez años en curso, la respuesta llegó de la pluma del propio virrey, quien recrudecía la presión sobre la justicia local. Muy probablemente, los derroteros del corregidor Hinojosa ya habían tomado notoriedad allende la ciudad de La Paz, poniendo al descubierto no solo la debilidad de los oficiales de la Real Hacienda sino también ciertas fisuras en la elite paceña.

\section{Episodio 7. La última oportunidad de los oficiales reales (1624)}

Como respuesta al exhorto del virrey, los oficiales de la Real Hacienda volvieron a la carga contra los fiadores de Hinojosa. En efecto, la acción de la causa retornó a los valles paceños. El mayordomo de la viña de Mecapaca, propiedad de los Barrasa y Cárdenas, argumentó que lo procedido de la producción agrícola fue destinado al mantenimiento general de la heredad. Los oficiales reales volvieron a exigirle las cuentas, que resultaron en un saldo deficitario. A pesar de que el 8 de noviembre de 1624 se designó un alguacil para embargar la viña, cinco días después el defensor de la Real Hacienda, Diego Núñez de la Raya, desestimó las cuentas otorgadas por el mayordomo quien, a su tiempo, protestaría las acusaciones en su contra con serios alegatos.

Asimismo, el defensor les solicitó activar la ejecución de los bienes de doña Isabel Vela y Acuña, viuda de don Antonio de Guzmán y Chirinos, el segundo fiador. Se trataba de la chacara de Moyobaya, cercana al pueblo de Magdalena de Sorata (corregimiento de Larecaja). Una vez el valle, el corregidor de Larecaja informó a su par de La Paz que se aún encontraba abierto un pleito por la dote de doña Isabel, que databa de 1614-1618. ${ }^{28}$ De esta forma, el 15 de noviembre de 1624 el segundo esposo de la viuda, el General don Sancho Díaz de Zurbano, encomendero de Achacachi, contradijo la requisitoria despachada por los jueces al corregidor de Larecaja para administrar la chacara de Moyobaya. En respuesta, estos se limitaron a incorporar a la causa los instrumentos probatorios presentados por Díaz de Zurbano y remitir lo actuado al defensor de la Real Hacienda.

\footnotetext{
${ }^{28}$ Los bienes del difunto don Antonio de Guzmán y Chirinos incluían "un esclavo negro llamado Augustin y un cavallo castaño de carrera y en una chacara de Laricaxa Moyovaya y en los tributos del pueblo de Guarina" (RNH, ff. 211v-212r), que según la ejecución cometida por el alguacil mayor Gregorio Suárez de Vitoria, realizada el 5 de enero de 1614 en el marco del pleito por la dote de doña Isabel, montaron 24.000 pesos corrientes. El 18 de mayo de 1615 los bienes fueron rematados en favor de Lorenzo Vázquez del Castillo por 4000 pesos corrientes, es decir, la tercera parte del avalúo inicial de la dote (RNH, ff. 216r-218v).
} 
Al día siguiente, el depositario general Pedro de Mena se dirigió a la estancia de Yrucunga, propiedad de don Antonio de Barrasa y Cárdenas, en busca de más cabezas de ganado para ejecutar. En los siguientes tres días, los yanaconas hallaron 140 vacas y 1.000 ovejas, que entregaron a Mena para su ejecución. En paralelo, el defensor de la Real Hacienda volvió a solicitar la presentación de las cuentas del mayordomo de la viña de Mecapaca, la desestimación del alegato de Díaz de Zurbano, el embargo de la chacara de Moyobaya y el envío de una carta requisitoria a Arequipa tras los pasos de Hinojosa. El 29 de noviembre, los oficiales de la Real Hacienda hicieron lugar al pedido del defensor, despachando la requisitoria con notificación a sus antecesores, responsables de la segunda huida del corregidor. Finalmente, el 2 de diciembre de 1624, enviaron al comisionado Pacheco Cerquera a tomar las cuentas del mayordomo de la viña de Mecapaca, resultando este expulsado de sus tareas de administración.

Las presiones del virrey surtieron su efecto. Los oficiales reales reiniciaron sus esfuerzos tanto para dar con el paradero de Hinojosa como para confiscar más bienes de los fiadores. Ante este avance, se encontraron con la misma reacción por parte de los representantes de los fiadores. El nuevo esposo de la viuda de un fiador (él mismo encomendero e hijo de otro "benemérito de la conquista") rechazó las exigencias de los oficiales reales. Desconocemos los tramos ulteriores del proceso debido a que el documento se interrumpe abruptamente. ${ }^{29}$

\section{Consideraciones finales}

La pluralidad de actores que intervinieron en el ajuste de cuentas contra el corregidor Martín Navarro de Hinojosa (en un número que supera las 80 personas) y los diferentes tipos de vínculos entablados entre ellos presentan una densidad tal que, por momentos, su lectura y análisis resultaron de difícil seguimiento. Los 234 folios del expediente constituyen una ventana de acceso a los derroteros de corregidores, oficiales reales, fiadores, caciques, testigos, mandatarios, viudas y podatarios, revelando el enrarecimiento del clima político ante el peculiar acontecimiento de la huida de un corregidor en pleno proceso de residencia.

Las tramas del poder local funcionaron a partir de la interacción de un conjunto de actores sociales motivados por sus intereses corporativos, quienes

\footnotetext{
${ }^{29}$ De hecho, el folio 234 se encuentra separado del expediente original, catalogado como ALP CR 1624 C3 D28. Hemos fatigado sin éxito los expedientes de los fondos Cajas Reales y Expedientes Coloniales del Archivo de La Paz hasta 1650 para dar con otros folios sueltos del proceso. Es probable que la resolución final del proceso haya sido consignada de manera sumaria en el margen superior izquierdo del primer folio del expediente, el cual se halla completamente deteriorado.
} 
procuraron reproducir e incrementar sus respectivas dotaciones de capital. Como señalamos al inicio, era indispensable contar con miembros notables de la elite paceña para concertar y concretar el ingreso, incorporación o reincorporación de un nuevo miembro del entramado político. ${ }^{30}$ En líneas generales, las fianzas se otorgaban en la seguridad de que, más allá de los "tratos, contratos y granjerías" que los corregidores impulsaran, se resguardarían los intereses de los garantes. En el caso aquí analizado, la escandalosa conducta de los corregidores Hinojosa y Gaitán "perturbó la práctica estilada" de relacionamiento político. Corregidor y fiadores constituían posiciones relacionales claves que se retroalimentaban cuando todo discurría "según costumbre"; cuando no era así, se activaban tanto los engranajes del dispositivo burocrático como los mecanismos de reestructuración de la red, poniéndose en evidencia las fisuras y los faccionalismos del campo político local para salvaguardar los intereses corporativos de un segmento de la elite paceña que monopolizaba los oficios capitulares en tanto "cabezas de república" (Agüero, 2005).

En tanto jueces de causa, los oficiales de la Real Hacienda de la Paz se hallaban entrampados en una encrucijada a cuatro frentes: (1) las autoridades superiores (virrey, audiencia, contaduría mayor), cuyas recurrentes órdenes exigían dar con el paradero del corregidor y/o ejecutar los bienes de los fiadores; (2) el defensor de la Real Hacienda, cuyo principal objetivo era ajustar las cuentas adeudadas para garantizar el cumplimiento de la residencia; (3) los fiadores y sus apoderados, quienes constantemente protestaban e impugnaban la ejecución de sus bienes; y (4) sus propios comisionados, quienes incansablemente retornaban a la ciudad con los pocos bienes confiscados o incluso con las manos vacías. En una posición de inferioridad, y siempre bajo la amenaza de varias temporadas en la cárcel pública, los caciques de los pueblos de reducción sujetos a tributo constituían (como era habitual) una "variable de ajuste", sin mucho margen de acción.

El proceso aquí analizado tuvo lugar durante una coyuntura atravesada por una clara redefinición de la política virreinal con respecto a los requisitos, incumbencias, competencias jurisdiccionales e incluso la vigencia misma del oficio de corregidor de indios y los alcances de los juicios de residencia, específicamente durante los gobiernos de los virreyes marqués de Montesclaros (1607-1615), príncipe de Esquilache (1615-1621) y marqués de Guadalcázar (1622-1629) (Lohmann Villena, 2001 [1957]: 530-537). A nivel local, durante el primer cuarto del siglo XVII la sociedad paceña también se vio impactada por los ecos de una supuesta rebelión liderada por el cacique de Caquiaviri en 1613, una sucesión de revisitas y retasas efectuadas entre 1619 y 1625 a varios

30 Dada la renovación generalmente bianual de los cinco corregidores de indios de la jurisdicción de La Paz, estimamos que cada diez años debían protocolizarse 25 escrituras de fianza. 
repartimientos lacustres para compensar los efectos disruptivos de epidemias, malas cosechas y "ausentismo indígena", un escandaloso encono durante la elección de alcaldes ordinarios de 1621 y la rebelión nativa de Songo y Challana de 1623-1625 (Saignes 1987; Espinoza Soriano 1998; Glave 2007; Morrone 2012, 2013b). Para futuras etapas de la investigación, procuraremos ponderar en qué medida los hechos del proceso contra el corregidor Hinojosa y sus fiadores pudieron verse condicionados por este crítico contexto político, como así también indagar en los alcances y las limitaciones de los mecanismos de integración de los poderes locales (en nuestro caso, los corregimientos bajo jurisdicción de la ciudad de La Paz) con instancias superiores del gobierno colonial, tales como la Audiencia de Charcas y la corte de Lima (Ponce Leiva y Amadori, 2008; Imízcoz Beunza, 2016).

Si la residencia tenía como objetivo ubicar a cada actor social en su respectiva posición con respecto a la autoridad regia, su despliegue "en el territorio" activó su potencial conflictivo, exponiendo álgidas disputas intraelite (Smietniansky, 2013: 183-189). En nuestro caso, asistimos a la consolidación de un bloque familiar, clientelar y (por lo tanto) político que se posicionó frente a los jueces oficiales de la Real Hacienda para rechazar de plano sus autos, despachos y comisiones. Exceder el análisis normativo de la residencia permite superar el "complejo de frustración" que supieron padecer las visiones institucionalistas ante la recurrente connivencia entre residenciados y residenciadores. En este sentido, queda pendiente la dilucidación de las relaciones existentes entre los oficiales de la Real Hacienda de La Paz y los notables vecinos, trabajo que podría enriquecerse a partir de un análisis sobre la fiscalidad en esa ciudad (comportamiento tributario de los repartimientos, dinámica administrativa de la Caja Real, perfil sociofamiliar e inserción de los oficiales reales en la red local, entre otros tópicos a desarrollar).

Por lo pronto, en nuestro caso, el "nivel de frustración" del proceso de residencia (si cabe tal denominación) fue relativo. De las cuentas tomadas por los oficiales de la Real Hacienda de La Paz, sabemos que el total del alcance adeudado por Navarro de Hinojosa ascendía a 10.176 pesos de plata ensayada (es decir, el equivalente a diez veces su salario anual) y 3.296 pesos de oro en polvo. Dado que, en el transcurso del proceso, los fiadores fueron ejecutados por un total de 7.600 pesos corrientes, que convertidos a ensayados equivalieron a 4.750 pesos, el resultado de la ejecución alcanzó a cubrir casi el $47 \%$ de la deuda en plata. De todos modos, las recurrentes huidas (preparadas por el propio corregidor y/o auspiciadas por sus allegados) imposibilitaron el despliegue del mecanismo residenciador al pleno, toda vez que no se convocaron testigos a la pesquisa (secreta o pública) ni se levantaron otros cargos (o, cuanto menos, esas etapas procesales no obran en la documentación relevada). 
Pero el análisis puede trascender la dicotomía de éxito/fracaso del procedimiento administrativo, habilitando caminos para abordar las formas específicas en que se articularon, encarnaron y territorializaron las relaciones de poder a escala local, regional y virreinal. Tanto la amplia movilidad espacial del corregidor Hinojosa a través del sur andino como los emprendimientos productivos de los fiadores y sus agentes se trazaron sobre los mismos esquemas de integración regional del "espacio del trajín” (ver Mapa 2). En este sentido, el conflicto desatado tras la huída del corregidor entre su sucesor y sus fiadores cobra otros niveles de complejidad al reparar en que todos ellos se disputaban los excedentes procedidos de la explotación de la mano de obra nativa y el abastecimiento de la plaza mercantil orureña.

Como resultante funcional de un entramado reticular, estos "juegos locales del poder" tensionaron los lazos de la propia elite paceña. Devenido en tablero para esos juegos, el lago Titicaca y sus corregimientos adyacentes constituyeron, a la luz de este estudio, espacios de luchas y conflictividad como efecto de la ruptura y "descompostura" de los "estilados" códigos de vinculación intraelite.

Buenos Aires, 26 de mayo de 2019.

\section{Bibliografía citada}

Acosta, Antonio (2014 [1979]). “El pleito de los indios de San Damián (Huarochirí) contra Francisco de Ávila (1607)", en Domínguez Faura, Nicanor (comp.) Prácticas coloniales de la Iglesia en el Perú, siglos XVI-XVII, Sevilla: Aconcagua Libros, pp. 331-368.

Agüero, Alejandro (2005). “Ciudad y poder político en el Antiguo Régimen. La tradición castellana", en Cuadernos de Historia, núm. 15, pp. 237-310.

Andrien, Kenneth J. (1986). "El corregidor de indios, la corrupción y el Estado virreinal en Perú (1580-1630)", en Revista de Historia Económica, vol. IV, núm. 3, pp. 493-520.

Angeli, Sergio H. (2012). “El juicio de residencia: documento inicial para la reconstrucción de la vida social y profesional de los oidores americanos (siglo XVI-XVIII)", en Revista Electrónica de Fuentes y Archivos, vol. 3, núm. 3, pp. 182196.

Angeli, Sergio H. (2014). “Un temprano juicio de residencia colonial: el Licenciado Juan Fernández, primer fiscal de la Audiencia de Lima", en Investigaciones y Ensayos, núm. 60, pp. 437-457. 
Assadourian, Carlos Sempat (1982 [1979]). “La organización económica espacial del sistema colonial”, en El sistema de la economía colonial, Lima: IEP, pp. 277-321.

Assadourian, Carlos Sempat (1987). “Los señores étnicos y los corregidores de indios en la conformación del Estado colonial", en Anuario de Estudios Americanos, núm. 44, pp. 325-426.

Bandieri, Susana O. (1996). "Entre lo micro y lo macro: la historia regional. Síntesis de una experiencia”, en Entrepasados, núm. 11, pp. 71-100.

Barnadas, Josep M. (1973). Charcas 1535-1565. Orígenes históricos de una sociedad colonial, La Paz: CIPCA.

Barnadas, Josep M. (1987). "Sobre las diferentes regionalidades coloniales: el caso charqueño (siglos XVI-XVII)", en Coloquio Estado y Región en los Andes, Cusco: Centro Bartolomé de Las Casas, pp. 15-28.

Barriera, Darío (2006). “Un rostro local de la Monarquía Hispánica: justicia y equipamiento político del territorio al sureste de Charcas, siglos XVI y XVII", en Colonial Latin American Historical Review, vol. 15, núm. 4, pp.377-418.

Barriera, Darío (2014). "Corregidores sin corregimientos: un caso de mestizaje institucional en Santa Fe del Río de la Plata durante los siglos XVII y XVIII", en Revista de Estudios Histórico-Jurídicos, núm. XXXVI, pp. 245-269.

Benedetti, Alejandro G. (2009). "Los usos de la categoría región en el pensamiento geográfico argentino", en Scripta Nova XIII, núm. 286. Disponible en: http://www.ub.es/geocrit/sn/sn-286.htm.

Castro Olañeta, Isabel (2013). “'Vuestra magestad se sirva de ordenar al governador que no apriete en las ordenanzas del visitador'. Gobierno colonial y poder local en la Gobernación del Tucumán (1603-1619)", en Bibliographica Americana, núm. 9, pp. 23-48. Disponible en:

https://www.bn.gov.ar/micrositios/revistas/bibliographica/bibliographicaamericana-1

Cook, Noble D. (1975). Tasa de la Visita General de Francisco de Toledo, Lima: UNMSM.

Cook, Noble D. (2003). “The corregidores of the Colca valley, Perú: imperial administration in an Andean región", en Anuario de Estudios Americanos, vol. 60, núm. 2, pp. 413-439.

Espinoza Soriano, Waldemar (1998). "La rebelión nativista de los cocaleros de Songo y Challana. 1623-1624", en Investigaciones Sociales, vol. 2, núm. 2, pp. 123177.

García Guzmán, Ana María (2014). Patrimonio y poder en la sociedad colonial. Las dotes de la ciudad de La Paz, 1585-1650, La Paz: CEPAA. 
Glave, Luis Miguel (1989). Trajinantes. Caminos indígenas en la sociedad colonial. Siglos XVI / XVII, Lima: Instituto de Apoyo Agrario.

Glave, Luis Miguel (1998). De Rosa y espinas. Economía, sociedad y mentalidades andinas, siglo XVII, Lima: IEP.

Glave, Luis Miguel (2007). “Fray Alonso Granero de Ávalos y los naturales andinos: debates sobre el destino de la sociedad colonial a inicios del siglo XVII", en Cuadernos Interculturales, núm. 8, pp. 15-50.

Imízcoz Beunza, José María (2016). “Las relaciones de patronazgo y clientelismo. Declinaciones de la desigualdad social”, en Imízcoz Beunza, José María y Artola Renedo, Andoni (coords.) Patronazgo y clientelismo en la monarquía hispánica (siglos XVI-XIX), Bilbao: Universidad del País Vasco, pp. 1941.

Lee, Bertram T. y Juan Bromley (1935-62). Libros de Cabildos de Lima, Lima: Concejo Provincial, 1935-1962, 23 vols.

Levillier, Roberto (1935). Don Francisco de Toledo, supremo organizador del Perú, Buenos Aires: Espasa Calpe, 3 vols.

Lohmann Villena, Guillermo (2001 [1957]). El corregidor de indios en el Perú bajo los Austrias, Lima: PCUP.

López Beltrán, Clara (1998). Alianzas familiares. Elite, género y negocios en La Paz, s. XVII, Lima: IEP.

Lorandi, Ana María (2000). “Las residencias frustradas. El juez Domingo de Irazusta contra el Cabildo de Salta”, en Andes, núm. 11, pp. 51-80.

Lourau, René (1970). El análisis institucional, Buenos Aires: Amorrortu.

Morrone, Ariel J. (2012). "De "señores de indios" a nobles rentistas: los encomenderos de La Paz (1548-1621)", en Surandino Monográfico, Segunda Sección de Prohal Monográfico, vol. II, núm. 2, Disponible en: http://revistascientificas.filo.uba.ar/index.php/surandino/article/view/5912/5255

Morrone, Ariel J. (2013a). "Curas doctrineros y caciques andinos en la construcción de legitimidades: las iglesias rurales de La Paz (Audiencia de Charcas, 1570-1630)", en Jahrbuch für Geschichte Lateinamerikas, núm. 50, pp. 2954.

Morrone, Ariel J. (2013b). “Estrategias estatales y liderazgo étnico en el corregimiento de Pacajes (1538-1620)", en Presta, Ana María (ed.) Aportes multidisciplinarios al estudio de los colectivos étnicos surandinos. Reflexiones sobre Qaraqara-Charka tres años después, La Paz: IFEA-Plural, pp. 343-372

Morrone, Ariel J. (2015a). “Tras los pasos del mitayo: la sacralización del espacio en los corregimientos de Pacajes y Omasuyos (1570-1650)", en Bulletin de l'Institut Français d'Études Andins, núm. 44, pp. 91-116. 
Morrone, Ariel J. (2015b). "Memoria en la sangre y en la tierra. Liderazgo, sucesión y territorialidad en el sur andino (corregimiento de Pacajes, 15701650)", en Indiana, núm. 32, pp. 205-234.

Morrone, Ariel J. (2016). “No todos los caciques fueron mallku. Mediación política truncada en los corregimientos de Pacajes y Omasuyos (Audiencia de Charcas, 1570-1630)", en Diálogo Andino, núm. 50, pp. 207-217.

Morrone, Ariel J. (2017). “El lago de los curas. Mediación sociopolítica y cultural en los corregimientos del lago Titicaca (1570-1650)", en Estudios Atacameños, núm. 55, pp. 183-202.

Morrone, Ariel J. (2018a). “Del registro documental al territorio colonial: discursos, prácticas y relaciones de poder en el lago Titicaca (1570-1630)", en Chungara. Revista de Antropología Chilena, vol. 50, núm. 2, pp. 273-287.

Morrone, Ariel J. (2018b). “Mujeres cacicales en el tablero colonial. Familia, parentesco y poder étnico en el lago Titicaca (1580-1750)", en Andes, vol. 29, núm. 1, pp. 1-31.

Pérez-Mallaína Bueno, Pablo E. (1997). El hombre frente al mar. Naufragios en la Carrera de Indias durante los siglos XVI y XVII, Sevilla: Universidad de Sevilla.

Presta, Ana María (1997). “Detrás de la mejor dote, una encomienda. Hijas y viudas de la primera generación de encomenderos en el mercado matrimonial de Charcas, 1534-1548", en Andes, núm. 8, pp. 27-46.

Presta, Ana María (2000). Encomienda, familia y negocios en Charcas colonial. Los encomenderos de La Plata, 1550-1600, Lima: IEP-BCRP.

Ponce Leiva, Pilar y Arrigo Amadori (2008). “Redes sociales y ejercicio del poder en la América hispánica: consideraciones teóricas y propuestas de análisis", en Revista Complutense de Historia de América, núm. 34, pp. 15-42.

Robles Bocanegra, Javier E. (2015). “El origen del 'cuerpo de república' indígena. Un análisis del discurso político del licenciado Castro sobre los corregimientos de indios del Perú, 1563-1569", en Nueva Coronica, núm. 5, pp. 93-112.

Sica, Gabriela (2014). "En torno al corregidor de Omaguaca. Atribuciones, competencias y disputas jurisdiccionales en el Tucumán colonial. Siglo XVI", en Sierra, María; Pro, Juan y Mauro, Diego (eds.) Desde la Historia. Homenaje a Marta Bonaudo, Buenos Aires: Imago Mundi, pp. 198-208

Saignes, Thierry (1987). “De la borrachera al retrato: los caciques andinos entre dos legitimidades (Charcas)", en Revista Andina, núm. 9, pp. 130-170.

Saignes, Thierry (1991). “Lobos y ovejas. Formación y desarrollo de los pueblos y comunidades en el sur andino (siglos XVI-XX)", en Moreno Yáñez, Segundo y 
Salomon, Frank (comps.) Reproducción y transformación de las comunidades andinas, siglos XVI-XX, Quito: Abya Yala, pp. 91-135

Sanz, Eufemio L. (1995). Cuatro mil vallisoletanos y cien poblaciones en América y Filipinas, Valladolid: Excelentísima Diputación Provincial. Disponible en: https://core.ac.uk/download/pdf/71527923.pdf

Smietniansky, Silvina (2007). "El juicio de residencia como ritual político en la colonia (Gobernación de Tucumán, siglo XVIII)", en Memoria Americana, núm. 15, pp. 71-101.

Smietniansky, Silvina (2013). Ritual, tiempo y poder. Una aproximación antropológica a las instituciones del gobierno colonial (Gobernación del Tucumán, siglos XVII y XVIII), Rosario: Prohistoria.

Solórzano Pereira, Juan de (1739 [1629]). Politica indiana, Madrid: Gabriel Ramírez. Disponible en: https://catalog.hathitrust.org/Record/009328207.

Stern, Steve J. (1986 [1982]). Los pueblos indígenas del Perú y el desafío de la conquista española. Huamanga hasta 1640, Madrid: Alianza.

Tord Nicolini, Javier (1974). "El corregidor de indios del Perú: comercio y tributos", en Historia y Cultura, núm. 8, pp. 173-214.

Trujillo, Oscar J. (2016). “Justicia mayor: los gobernadores de Buenos Aires y la administración de Justicia en el siglo XVII. Una aproximación desde sus Juicios de Residencia", en Revista de la Escuela de Historia, vol. 15, núm. 2. Disponible en: http://www.rehunsa.com/revista15v02-art03.htm 